\title{
Naturaleza jurídica y procedimiento de aprobación de las tarifas en el servicio de abastecimiento de agua cuando el servicio se gestiona por empresas de capital mixto o enteramente público
}

\author{
Antonio Domínguez Vila \\ Secretario S. de Admón Local. \\ Prof. Titular de Derecho Constitucional.
}

Sumario: I. LEGISLACIÓN APLICABLE. II. POSICIÓN DE LA DOCTRINA. III. ESTABLECIMIENTO, FIJACION Y MODIFICACIÓN DE LOS PRECIOS PÚBLICOS. IV. POSICIÓN DE LA JURISPRUDENCIA. V. CONCLUSIONES.

\section{LEGISLACIÓN APLICABLE}

El artículo 6.1 de la Ley de Bases de Régimen Local establece el principio de descentralización y desconcentración como medio de que las Entidades Locales sirvan los intereses públicos que le están encomendados con sometimiento pleno a la Ley y al Derecho; el artículo 25 establece, en su punto primero, como competencia de los municipios el suministro de agua, así como el servicio público de alcantarillado y tratamiento de aguas residuales. El artículo 85, en su punto primero, entiende que son servicios públicos locales todos aquellos que tiendan a la consecución de los fines señalados como competencia de las entidades locales; en su punto segundo establece que los servicios públicos locales pueden gestionarse de manera directa o indirecta, refiriéndose respecto a la primera modalidad el punto tercero c) a la gestión por sociedad cuyo capital pertenezca íntegramente a la entidad local y el cuarto, respecto a la segunda, a las diversas formas que de manera indirecta caben a la sociedad mercantil, cuyo capital pertenezca sólo parcialmente a la entidad local. Por último, el artículo 86, en su punto tres, que crea la reserva en favor de las entidades locales con carácter de monopolio el servicio de abastecimiento y depuración de aguas. 
El Texto Refundido de disposiciones vigentes en materia de régimen local, en su artículo 103, prescribe los límites jurídico-públicos a la constitución de sociedades municipales y el 104.2 establece que el acuerdo constitutivo de las sociedades mixtas podrá establecer las especialidades internas, tanto estructurales como funcionales que, sin perjuicio de terceros, exceptúan la legislación societaria aplicable, en la medida necesaria para promover y desarrollar la empresa mixta de carácter mercantil o cooperativo, lo que constituye un primer freno a la aplicación en masa del Derecho mercantil a las sociedades públicas gestoras de servicios públicos. Prescribiendo el artículo 106, a continuación, que los actos de gestión del servicio, en sus relaciones con los usuarios, estarán sometidos a las normas del propio servicio o, en su caso, a la legislación general que regule la materia, que ha de ser siempre administrativa. En el artículo 155 del Reglamento de Servicios de las Corporaciones Locales, se establece en su punto primero, que en los servicios prestados directamente por la Corporación, las tarifas que hayan de satisfacer los usuarios, tendrán la naturaleza de Tasa y serán exancionables por vía de apremio y, en su punto segundo, que si el servicio se prestase con arreglo a las formas de Derecho privado y en especial por medio de Sociedad Anónima, las tarifas tendrán el carácter de precio o merced sometido a las prescripciónes civiles y mercantiles.

Tras el silencio de la legislación básica sobre el tema, en la legislación autonómica, dejando aparte leyes de desarrollo del régimen local como la de la Comunidad Autónoma Canaria, en la que, dada su escasa calidad técnica en este tema como en otros muchos, nada se aclara al respecto, en otras leyes, sí se avanza algún criterio sobre la cuestión, así el art. 240.3, que no establece ninguna excepción en materia de aprobación de tarifas, y el 251 de la Ley Municipal y de Régimen Local de Cataluña $8 / 87$, de 15 de abril, establece que las tarifas de los servicios públicos tendrán la consideración de precio, no especificándose si público o privado, cuando se presten los servicios a través de una sociedad mercantil; asimismo, el artículo 198.2 de la Ley Foral de Administración Local de la Comunidad Autónoma de Navarra 6/1990, de 2 de julio, establece que en los casos de gestión indirecta mediante sociedad mixta, en los Estatutos Sociales deberá delimitarse el carácter de la empresa en cuanto al modo gestor de un servicio público, así como las facultades reservadas al ente público o a sus representantes en los órganos directivos de la sociedad, estableciéndose, en el punto tres del mismo, artículo que se requerirá la conformidad de la entidad local en todo caso para la modificación del acto de constitución, de los estatutos de la sociedad, o la concertación de operaciones de crédito y aprobación de cuentas de resultados y balances, de lo que parece deducirse que son las normas 
NATURALEZA JURIDICA Y PROCEDIMIENTO DE APROBACIÓN DE LAS TARIFAS DEL SERVICIO DE AGUAS

estatutarias las adecuadas para indicar el procedimiento de aprobación de las tarifas, con la conformidad, en todo caso, de la entidad local.

Desde la perspectiva tributaria, la Ley $39 / 88$, de 28 de diciembre, Reguladora de las Haciendas Locales, en su artículo 48.2, faculta a las entidades locales para que atribuyan a sus organismos autónomos y consorcios la fijación de los precios públicos, por lo que, sensu contrario, con una interpretación exegética y no finalista, podría deducirse la exclusión de dichos precios públicos de las entidades mercantiles cuyo capital sea total o parcialmente propiedad de una entidad pública, teniendo éstos carácter o naturaleza de ingreso de Derecho privado. En este sentido, la letra c) del artículo 24 de la Ley 8/1989, de 13 de abril, de tasas y precios públicos (aplicación supletoria en el ámbito local según su Disposición Adicional Séptima), al expresar que tendrán la consideración de precios públicos las contraprestaciones pecuniarias que se satisfagan por la prestación de servicios, o realización de sus actividades, efectuadas en régimen de Derecho público, cabe interpretar también, sensu contrario, que debería de entenderse que no tienen la consideración de precios públicos las contraprestaciones económicas efectuadas por servicios y desarrollo de actividades efectuadas por la Administración, pero gestionadas por entes de Derecho privado.

En todo caso, la legislación tributaria lo que hace es ignorar la naturaleza de las tarifas de los servicios gestionados por empresas, lo que abunda en el tradicional desconocimiento de la legislación tributaria de los preceptos concordantes de la normativa administrativa general.

En el orden presupuestario, a las entidades mercantiles dependientes de una Administración Pública, se les excluye del régimen aplicable a las entidades locales, y de sus organismos autónomos de carácter administrativo. Así, y aunque en el artículo primero del Real Decreto $500 / 1990$, de 20 de abril, se determine que sus normas son de aplicación a las entidades mercantiles cuyo capital social pertenezca total o mayoritariamente a la entidad local, es preciso estar a lo dispuesto en el artículo 111, por cuanto expresa que las sociedades mercantiles se regirán por las normas del Derecho privado, salvo en materias específicamente reguladas en el propio Real Decreto. En este sentido, la letra d) del artículo 2, y la c) del artículo 5, determinan que los estados de previsión de ingresos y gastos de las sociedades mercantiles cuyo capital social pertenezca íntegramente a la entidad local compondrán el presupuesto general de la entidad. Asimismo, en el número $5 .^{\circ}$ del artículo 18 , viene a expresar que el acuerdo de aprobación, que será único, habrá de detallar los presupuestos que integran los presupuestos municipales conso- 
lidados. En este ámbito, la única referencia que se hace respecto a las sociedades mercantiles, cuyo capital sea de la entidad local, es la contenida en el artículo 12, al determinar que se unirán como anexos al presupuesto general los programas anuales de actuación, inversión y financiación de las sociedades mercantiles de cuyo capital social sea titular único o participe mayoritariamente la entidad local. Con lo que parece que en la legislación presupuestaria existe también una total y absoluta remisión al Derecho privado, en cuanto a los presupuestos de las sociedades mercantiles total o parcialmente públicas. Valen aquí las mismas razones esgrimidas para la legislación tributaria, ya que la clasificación a efectos presupuestarios de las tarifas, parece coherente que a los efectos presupuestarios, no se confundan los ingresos y gastos de las sociedades anónimas municipales para su propia eficacia y viabilidad.

\section{POSICIÓN DE LA DOCTRINA}

Ante la falta de regulación clara por parte del Derecho positivo, habrá que efectuar una pesquisa por la doctrina para poder lograr alguna conclusión sobre el tema. Ya Fernando ALBI en el antiguo y fundamental libro sobre las formas de gestión de los servicios públicos ${ }^{1}$, se planteaba respecto a la declaración del artículo 155.1 del Reglamento de Servicios de las Corporaciones Locales, que la tarifa de prestación de servicio por medio de empresas mixtas tendrá la naturaleza de tasa y será exaccionable por la vía de apremio, debiendo armonizarse ello con la naturaleza mercantil de la modalidad de empresa mixta y su consiguiente sumisión al Derecho privado; existiendo en este caso una intromisión de un régimen netamente administrativo en un elemento básico para su economía, es decir, los precios. Para AlBi resultaba absurdo que el propio artículo 155 del Reglamento considerara de carácter privado las tarifas de las empresas de forma mercantil, cuando el capital de la misma pertenezca íntegramente a la Administración, mientras que se atribuye naturaleza pública precisamente a los casos en que a la forma mercantil se le agrega la colaboración de los particulares, esto es, cuando la naturaleza privada ya no es meramente una forma de gestión del servicio meramente formal. Para el propio ALBI ${ }^{2}$, ante el hecho que el art. 155.3 hable de precio o merced, pero el núm. 1 del mismo precepto lo haga de devolver la naturaleza jurídica de la tarifa al Derecho

\footnotetext{
1 ALBI, Fernando; Formas de Gestión de los Servicios Públicos, Editorial Aguilar, pág. 429. Madrid 1960.

2 AlBI, op. cit., pág. 353.
} 
público, la solución se encontraba en el desarrollo del artículo 153 del Reglamento de Servicios de las Corporaciones Locales, ya que las escrituras de constitución de las empresas mixtas podrían estipular la fórmula de revisión de las tarifas. Más recientemente Alonso UREBA 3 expresa que, como principio, no se podrá aplicar a las sociedades de participación local el régimen de tarifa (art. 107 TRRL), sino el de precio del producto o servicio prestado (criterio de retribución económica), construyendo la tesis de que, en caso de convenio expreso o concesión entre la entidad y la Empresa, de la que ésta forma parte, sí podría darse lugar a la aplicación de tarifas conforme al 107 del TRRL. En el caso concreto de las empresas mixtas y relacionando el artículo 111.2 y 3 del Reglamento de Servicios con el 108 del Texto Refundido, que en su apartado b) determina los precios de prestación del servicio, así como los plazos y condiciones de su revisión; se advierte que hay que diferenciar entre una mera participación de la Entidad local en la sociedad, donde la influencia de la política de precios la hará la entidad local desde su posición de socio mayoritario, pero si a la participación de capital de la entidad local se le une un convenio externo entre dicha entidad y la sociedad, por ejemplo, una concesión o arrendamiento del servicio, cabrá en base a dicho convenio una intervención mayor, entrando en juego el concepto de canon, concretando respecto a las tarifas que el artículo 107 del Texto Refundido, referido al régimen de determinación de las mismas, no es aplicable al régimen de la sociedad de participación local, pues no es el concepto de tarifas sino el de precio del producto servido el que juega en relación con entes de carácter jurídico-privado como son las sociedades, cabiendo, sin embargo, un régimen de concierto, concesión o convenio de la entidad local y una sociedad mercantil, en la que a su vez participe la entidad local, lo que puede dar lugar en algunos casos a la aplicación del régimen de tarifas previsto en el artículo 107 del Texto Refundido. Añade UREBA, interpretando los artículos 2 y 3 del artículo 104 del Texto Refundido, que se refiere a las especialidades que se han de expresar en el acuerdo constitutivo y en la escritura de constitución, reservándose en su caso las facultades que procedan quienes representen en la empresa a la entidad local, que es donde cobran sentido las funciones de control o influencia pública sobre la sociedad, introduciendo dicha escritura el derecho de la entidad local a la designación o revocación de consejeros, y al margen de la Junta y Consejo de Administración, el derecho de dar instrucciones vinculantes a los Consejeros designados a instancia del ente público y otras formas similares.

3 UREBA, Alonso; «La sociedad mercantil de capital como forma de gestión de los servicios locales", en Tratado de Derecho Municipal, Tomo II, Editorial Cívitas, pág. 1367. 
En discrepancia parcial con este autor, ha de manifestarse que, a los efectos de la contraprestación del servicio público, tanto da el hecho de que no exista un convenio o concesión con la empresa local, como que sólo participe el ente en los beneficios como socio e influya en la gestión empresarial por medio de la presencia mayoritaria en los órganos de dirección. Ha de partirse de la diferencia, ya indicada por el autor, de las relaciones externas e internas de la gestión de los servicios públicos por medio de empresas sometidas al Derecho privado, pero también ha de introducirse una segunda clasificación, en el ámbito de las relaciones externas, en la fijación de los precios del servicio entre empresas de capital íntegramente público y empresas de capital mixto.

Esto es, en la gestión de servicios públicos por medio de sociedad de Derecho privado, las relaciones internas de la misma se deben de someter al Derecho privado, con los límites ya estudiados de la formación de la voluntad de la Administración de la que dependen. En idéntica medida, las relaciones externas de la empresa deben ser sometidas al mismo régimen jurídico que cualquier otra sociedad mercantil. Sin embargo, en el concreto tema de la fijación de precios, se debe de diferenciar entre empresas públicas que ejercen actividades económicas, de las previstas en el art. 97 del TRRL, y las gestoras de servicios públicos con vocación de monopolio y de necesaria prestación por la Administración, como es el agua y el saneamiento, donde el principio de interés público debe de modular e intervenir en la fijación del precio del servicio.

En el ámbito tributario local, ya Collado YuRrita M. A. y Giménez REYNA E. entendieron lo deficitario de la regulación de la Ley de Haciendas locales (art. 2.1, e), en cuanto a la configuración de la naturaleza jurídica de los precios públicos, estableciendo un recurso cuyo régimen jurídico es, en parte, el de un tributo y, en parte, el de un precio ${ }^{4}$. Para ARNAL SURIA 5 conforme a lo previsto en la Ley de Haciendas Locales parece claro que las tarifas del servicio de abastecimiento de agua tienen la naturaleza de precio público en contraposición con las tasas, todo ello conforme a lo previsto en los artículos 41 a 48 de dicha Ley, por lo que la figura de ingreso público no tributario es la correctamente aplicable a los servicios prestados por la Administración pero gestionados por los particulares, por lo que su contraprestación no reviste la

\footnotetext{
4 Collado Yurita Miguel Angel y Giménez Reyna Enrique, La Nueva Hacienda Local española, Edt. Cívitas 1990, pág. 84.

5 ARnal SURIA S., Iranzo Alarcón, L., Los nuevos Impuestos municipales y otras exacciones de Derecho público de las entidades locales, Edt. Siete, Valencia 1990. pgs. 55 a 73.
} 
NATURALEZA JURIDICA Y PROCEDIMIENTO DE APROBACIÓN DE LAS TARIFAS DEL SERVICIO DE AGUAS

forma de tributo sino de precio; sin embargo, este autor reconoce que este planteamiento no es unánimemente aceptado por la doctrina. El concepto de precio público viene definido, como se ha dicho, en la Ley Reguladora de las Haciendas Locales, coincidiendo en lo esencial con el artículo 24.1 de la Ley 8/89 de Tasas y Precios Públicos, estableciendo la consideración de precios públicos a las contraprestaciones pecuniarias que se satisfagan por la prestación de servicios públicos o actividades administrativas que no sean de solicitud o recepción obligatoria, siendo éste el elemento definitorio que lo separa de la tasa.

Desde otro punto de vista, MARTínez Giménez ${ }^{6}$ define el precio privado, como el precio de mercado obtenido por la gestión o administración de su propio patrimonio, por la Administración Pública, sin la prevalencia del interés público, sino siguiendo criterios de conveniencia económica para conseguir beneficios, encuadrando la naturaleza de los precios públicos en la contraprestación de servicios públicos, definiéndolos como aquellos «... que dan un ingreso global igual al coste total de la producción, pero la distribución de dicho coste entre cada usuario se realiza con criterios sociales" 7 .

Para esta autora, los criterios de distinción entre uno $\mathrm{u}$ otro precio estriban, por un lado, en el interés público en presencia, ya que cuanto mayor carácter de interés colectivo tenga el servicio público, menor exigencia de equiparación entre coste más beneficio debe tener la tarifa y, por lo tanto, debe de considerarse precio público y, por otro, en que en la aplicación de los precios privados, la Administración, debe reconocer la inexistencia de cualquier clase de imperium en las relaciones jurídicas que de los ingresos se deriven. Esto nos lleva, en el caso del servicio objeto del presente trabajo, a recurrir al criterio de la esencialidad de la prestación del mismo, como criterio de delimitación de su carácter de interés colectivo ${ }^{8}$.

Por lo que, si bien el art. 24.1 de la Ley de Tasas y Precios Públicos exige que las prestaciones se realicen en régimen de Derecho público para poder aplicarse precios públicos, por lo que, sensu contrario, en el caso de sociedades mercantiles sólo caben precios privados, justo es reconocer, junto con la autora citada, la contradicción con el art. 26 de

\footnotetext{
${ }^{6}$ Martinez Giménez, Consuelo.- Los precios públicos, Cívitas Madrid, 1993.

7 MARTínez Giménez, op. cit., págs. 21 y 22.

8 Garcla de ENTERRfa, "La Naturaleza de la tasa y las tarifas de los servicios públicos», RAP n. ${ }^{\circ}$ 19. pág. 129 y ss.
} 
la misma norma legal que los califica de públicos en el caso de organismos autónomos (art. 24) en relación con el requisito c) del art. 24, ya que el criterio de la voluntariedad no sólo es meramente formal, puesto que desde un punto de vista material se trata de servicios esenciales para la sociedad actual, resultando ocioso subrayar el sacrificio de su renuncia, como se trata del servicio de abastecimiento de agua domiciliario ${ }^{9}$, sino que toda la legislación sectorial en materia de habitabilidad de viviendas y de condiciones higiénico-sanitarias exige la presencia de abastecimiento de agua corriente para su uso por persona humana.

En la doctrina administrativista, destaca SOSA WAGNER ${ }^{10}$ para quien la denominación de la tarifa del servicio prestado, con arreglo a las formas de Derecho privado de precio o merced, empleada por el 155. 2 del Reglamento de Servicios y el 107 del Texto Refundido, no es una terminología legal excesivamente clara, por cuanto si el servicio se presta con arreglo a las formas de Derecho privado, el precio o merced actúa sometido a prescripciones civiles o mercantiles, aunque en ese precio o merced existen componentes públicos, no entrando a valorar este autor la naturaleza jurídica de precio público o privado de la tarifa de los servicios públicos gestionados por empresas mixta o enteramente municipal; sin embargo, sí incide el autor en cuáles son los principios básicos que han de contenerse en la tarifa del servicio: - en primer lugar, el de igualdad en virtud de lo previsto en el artículo 150 Reglamento de Servicios, - en segundo lugar, el de trato diferenciado o adecuación de la tarifa a los sectores sociales más débiles (art. 150. 2 RSCL), —en tercer lugar, el de autosuficiencia, que quiere decir financiación propia del servicio, lo que incluye no sólo la igualación de los costos con los ingresos, sino la posibilidad de hacer frente a nuevas inversiones, constitución de fondos y reservas y obtención de beneficios en su caso, puesto que, en virtud del artículo 97.1 b) del Texto Refundido, es lícita la obtención de beneficios.

\section{ESTABLECIMIENTO, FLJACIÓN Y MODIFICACIÓN DE LOS PRECIOS PÚBLICOS}

Según el artículo 48.1 de la Ley de Haciendas Locales el establecimiento o modificación de los precios públicos corresponderá al Pleno

\footnotetext{
${ }^{9}$ Martínez GimÉnez, op. cit., pág. 70.

10 Sosa Wagner, Francisco; La Gestión de los Servicios Públicos Locales, págł 183 a 191 , Editorial Cívitas, Madrid 1992.
} 
de la Corporación sin perjuicio de las delegaciones procedentes en la Comisión de Gobierno. En el punto 2 de dicho artículo, se establece que la entidad local podrá atribuir a sus organismos autónomos o consorcios la fijación de los precios públicos correspondientes a los servicios que dichos organismos gestionen. En ambos supuestos, se ha de enviar al ente local copia de la propuesta y del estado económico del que se desprenda que los precios públicos cubren el coste del servicio; ha de hacerse notar que en el artículo 48 no se hace ninguna referencia a qué ocurre cuando la atribución de los servicios se hace a sociedades mercantiles de capital parcial o totalmente en manos de la Administración Pública. Respecto al procedimiento, ARNAL SURiA ${ }^{11}$ indica que el establecimiento, fijación y regulación de los precios públicos no tendrá naturaleza de ordenanza fiscal, por lo que no cabe acudir al procedimiento regulado en los artículos 15 y 19 de la Ley de Haciendas Locales, produciéndose a este respecto dos tesis, la sostenida por el Ministerio de Hacienda que establece que el procedimiento que ha de seguirse es el previsto en el artículo 49 y 70.2 de la Ley Reguladora de las Bases de Régimen Local en relación con el 111 del mismo texto, esto es, el referente a las ordenanzas locales no tributarias, lo que conllevaría un trámite que comprendería sucesivos acuerdos plenarios provisional y definitivos, seguidos por edictos a publicar en el Boletín Oficial de la Provincia, para la aprobación de la Ordenanza y tarifas correspondientes, precisando la modificación de éstas y aquélla el mismo trámite que para su establecimiento y fijación inicial. La segunda tesis sostenida por ARnal Suría se basa en que la Exposición de Motivos de la Ley Reguladora de las Haciendas Locales apartado 3 párrafo trece in fine establece el deseo de instrumentar un sistema de precios públicos como recurso no tributario, que dote al régimen financiero municipal de mayor dinamismo y de más capacidad de adaptación a la vida económica. En efecto, y si en virtud de la modificación de los artículos 101 y 111 de la Ley $7 / 85$, se ha simplificado el procedimiento de tramitación de las ordenanzas fiscales, parece un contrasentido que se pueda entender que los precios públicos están somẹtidos a un procedimiento aún más largo y proceloso que el de los citados artículos, pues los citados arts. 49 y 70.2, establecen más trámites que en el regulado por la Ley de Haciendas Locales, porque exige la interposición de un recurso de reposición contra la aprobación definitiva de las ordenanzas, mientras que en las fiscales procede directamente el contencioso-administrativo. Y además, según este autor, en el caso de las ordenanzas del artículo 49 de la Ley 7/85 la competencia para su aprobación es del Pleno con caracter inde-

11 ARnal Surta, op. cit., pág. 70. 
legable, mientras que, por el contrario, el artículo 48 de la Ley de Haciendas Locales establece la posibilidad de delegación del Pleno en la Comisión de Gobierno, por lo que, concluyendo, no es concebible que dos leyes vigentes que se han producido bajo el mandato de Parlamentos de muy semejante e idéntica orientación política, pudieran tener contradicciones tan graves, por lo que para ARNAL SURIA han de extraerse las siguientes conclusiones:

a) Que los precios públicos no necesitan una previa existencia de la correspondiente ordenanza fiscal, sino que basta la adopción del acuerdo de su establecimiento con la simultánea fijación de los respectivos importes a cobrar, eso sí, previo acuerdo del Pleno de la Corporación que precisa para su efectividad de la correspondiente publicación en el Boletín Oficial de la Provincia, lo que viene exigido no ya por los artículos de la Ley de Haciendas Locales sino por el artículo 46 de la Ley de Procedimiento Administrativo, y añade que la regulación de la exención de los precios públicos se efectuará, al no existir ordenanza sino sólo tarifas aprobadas, en la forma en que se ha dicho, de acuerdo con los preceptos de los arts. 41 a 47 de la Ley de Haciendas Locales y en lo que éstos no prevean, por los aplicables del Título tercero de la Ley $8 / 89$, de Tasas y Precios Públicos.

b) La titularidad de las competencias para el cobro de los precios públicos debe corresponder a la respectiva entidad local sin restricción ni excepción alguna; por la misma razón de inaplicabilidad a su ámbito de régimen regional de los tributos locales tampoco le son de aplicación los mecanismos de delegación de competencias y de colaboración entre Administraciones tributarias. Así, en consecuencia, para el cobro de un precio público por una entidad distinta de la titular de aquél, y, por ende, de la competencia, queda deferida a las normas generales de régimen local en materia de delegación de competencia o colaboración entre Administraciones y la gestión de cobro de los mismos deberá llevarse a cabo con arreglo a las normas generales de gestión de los recursos de Derecho público de las entidades locales, por lo que se aplicará el apartado segundo del artículo 2, de la Ley de Haciendas Locales y el apartado tercero del artículo 47 de la misma norma.

En el caso de empresas municipales o mixtas gestoras del servicio público, el precio público debe ser aprobado por la Junta General de la misma a propuesta del Consejo de Administración, con las posibles variantes que dispongan los Estatutos Sociales, debiendo preverse, en el caso de las Empresas Mixtas, que el representante de la Corporación 
en la Junta General sea el Presidente o un número reducido de miembros, que ostenten delegación suficiente, de lo contrario, será preceptivo una información o conocimiento al Pleno del Ente local, circunstancia que no ocurre con las empresas municipales pues su Junta es el Pleno.

En cuanto a su naturaleza de precio público o privado existe una carencia de solución normativa expresa, según reconoce toda la doctrina, por lo que se propone una interpretación de la cuestión. Para RUBIO DE URQUía y CORDERO LÓPEZ ${ }^{12}$, la aprobación de los acuerdos de establecimiento y divulgación de los precios públicos debería hacerse de acuerdo con el procedimiento de aprobación de ordenanza de las entidades locales del artículo 49 de la Ley 7/85.

Respecto a la competencia y procedimiento para la aprobación de los precios públicos, para este autor corresponde al Pleno de la Corporación Local, si bien se podrá atribuir a los organismos autónomos, no aclarando si en el caso de las empresas públicas, la aprobación de la tarifa por el órgano asambleario, la misma de la Junta General a propuesta del Consejo de Administración, requiere además la aprobación definitiva o conocimiento del Pleno del ente administrativo matriz.

Respecto al trámite de la aprobación superior como fiscalización de distinta Administración Pública, a la que se refieren los artículos $97.1 \mathrm{~b}$ in fine y 97.2 del Texto Refundido y la legislación general de precios, ya que el servicio que se presta está incluido en las normas generales de ordenación económica, en el caso de precios autorizados, vigilados y comunicados, según Sentencia que cita del Tribunal Supremo, de 15 de febrero de 1988, para este autor, la Sentencia de 25 de noviembre del 88 , resuelve el problema de los límites en que ha de moverse esta aprobación de la Administración superior. A este respecto de la aprobación de la Administración superior, la última norma vigente en materia de servicio está contenida en el artículo 8.10 , del Decreto $3477 / 74$, de 20 de diciembre, reproducido por el Decreto 2226/77, de 27 de agosto, desarrollado mediante Orden del entonces Ministerio de la Gobernación, de 30 de septiembre de 1977. En estas normas se ratifica la sujeción de las tarifas a régimen de precios autorizados, exigiéndose para su modificación los siguientes pasos proce-

12 Rubio de Urouta y Cordero López, Comentarios a la Ley de Haciendas Locales, págs. 209 y ss. Edt. Abella. 
dimentales: la propuesta del organo gestor, el informe motivado del Pleno de la Corporación sobre la modificación solicitada, dentro de los treinta días siguientes y la elevación de ambos a las Comisiones de Precios, entendiendo esta última como órgano de la respectiva Comunidad Autónoma. El informe emitido por el Pleno de la Corporación Local resulta vinculante, en cuanto al tope máximo de la tarifa propuesta, aunque la Comisión Autonómica puede aprobar una tarifa superior, pudiendo aplicar a este expediente la norma del silencio administrativo positivo de tres meses. A pesar de esa antelación de esta normativa frente a la Ley de Bases de Régimen Local y a la Ley de Haciendas Locales y ante la ausencia de una norma de adecuación y la falta de claridad en la doctrina sobre la naturaleza jurídica de las tarifas, parece lo más sensato que, previa la aprobación de las mismas por el órgano de la empresa mixta competente, Junta General, sea sometida al Ayuntamiento Pleno para dación de cuenta, y remitidas para su autorización por la Junta de Precios de la Comunidad Autónoma correspondiente, puesto que, en caso contrario, cualquier usuario podría negarse a pagarla e impugnar su validez $y$, en tal caso, el peso de la prueba de demostrar la vigencia de las normas caería sobre el servicio.

\section{POSICIÓN DE LA JURISPRUDENCIA}

De la jurisprudencia recaída cabe inferir una débil línea argumental de considerar la naturaleza jurídica de dichas tarifas como precio público, ya que, por ejemplo, en la Sentencia de 19 de junio de 1989, el Tribunal Supremo considera a las tarifas de abastecimiento de agua potable como precios públicos de índole política, en cuanto tratan de proteger a los usuarios y, por otro lado, la Sentencia de 3 de mayo de 1984 (Aranzadi n. ${ }^{\circ}$ 1884) establece que la circunstancia de que los servicios municipales sean prestados mediante concesión otorgada a empresa mixta no impide que las percepciones de la empresa concesionaria tengan la consideración de contraprestaciones por los servicios prestados. La Sentencia de 23 de junio de 1989, en su fundamento jurídico tercero, justifica la norma administrativa de las tarifas máximas, en la necesaria declaración de voluntad de la Administración, que permita a la empresa suministradora de aguas exigir a los usuarios de tal suministro un precio público. Precio que deriva esencialmente de la relación inter partes, y que su determinación a través de las tarifas precisa de una valoración, tanto de su oportunidad en el contexto de la economía nacional, como en relación con el interés que la Administración por mandato legal debe tutelar. 
NATURALEZA JURIDICA Y PROCEDIMIENTO DE APROBACIÓN DE LAS TARIFAS DEL SERVICIO DE AGUAS

\section{CONCLUSIONES}

Parece más adecuado calificar la naturaleza jurídico de las tarifas aplicables a los servicios encomendados a empresas mixtas como precios públicos por el interés general que subyace en la fijación de las mismas, cuyos requisitos están sujetos a revisión por la jurisdicción contencioso-administrativa, según se ha expresado en la brillante Sentencia de 29 de septiembre de 1986 (Aranzadi n. ${ }^{\circ}$ 6097), que han sido reproducidos por la doctrina. Aunque la escritura de constitución y los estatutos sociales intenten excepcionarlo del régimen administrativo para aplicar la legislación privada, como estimaba Alonso UREBA, no debe detraerse del conocimiento a la Administración titular de la competencia del servicio, que podrá tener la consideración de ratificación del acuerdo de la Junta General producida, en la que está representada la Corporación Municipal y en tanto la legislación de precios autorizados lo exija, de la preceptiva aprobación por parte del órgano autonómico de precios.

En este sentido, se ha pronunciado recientemente el Tribunal Supremo en Sentencia de 21 de Enero de 1993 (Aranzadi 393), en la que somete las tarifas del servicio de agua potable a la posibilidad de su exacción por la vía de apremio, (el servicio se prestaba por medio de gestión directa del Ayuntamiento), atribuyéndosele por el Tribunal la naturaleza jurídica de: «... tasa, por una parte, y de precio, por la otra; sin que ambos calificativos sean incompatibles entre sí, al ofrecer uno y otro diferentes objetivos o finalidades públicas que determinan una situación de concurrencia o yuxtaposición de competencias atribuidas a poderes distintos: la tarifaria a la Administración Local y la política de precios a la Comunidad Autónoma del caso...». Añadiéndose a los razonamientos del Tribunal que, también según la forma pública o privada de prestación del servicio, variará la naturaleza de la tarifa. 


\section{Sección Crónicas}

REALA-1994, núm. 263. DOMINGUEZ VILA, ANTONIO. NATURALEZA JURIDICA Y PROCEDIMIEN... 
